\title{
Hydrological Study of Fresh Water Pond At Kakinada Rural Village, P.Venkatapuram, E.G.Dist, Andhrapradesh.
}

\author{
Y.Ayyanna, Y.Narayudu \\ Lecturer in Zoology, Ideal College of Arts \& Sciences, Kakinada \\ Research Scholar in Adikavi Nannaya University, Rajahmundry,East Godavari District, Andhra pradesh. \\ M.pharmacy,Aditya institute of pharmaceutical science \& research, surampalem
}

\begin{abstract}
This paper present to study of the Hydrological study of fresh water pond at Kakinada rural villege, P. Venkatapuram, East godhavari dist, Andhrapradesh monthaly changes in Hydrological study of $\mathrm{pH}$, Temparachure, Dissolved oxgen, Carbondioxied, Chorides, Carbonates and Bicarbonates. Were analyzed for a periods of on year from $1^{\text {st }}$ january 2012 to $31^{\text {st }}$ december 2012. All parameaters with in the permissible limits. The results indicate that the P. Venkatapuram pandu polluted and can be used for pomestic, Irrigation and piscicuture.
\end{abstract}

Key Words :- Hydrological study of fresh water pond.

\section{Morphometry:}

The pond is almost oval in shape with an extent of 50 acres above and It is surrounded by small herbs and shrubs on all sides. There are no trees giving shade to the pond. Hence the sunlight will fall directly on the pond water, so that the water is subjected to diurnal and seasonal temperature fluctuations. Consequently, the conditions, the conditions of living organisms also vary. The area of the pond is roughly. The depth of the pond is about 7 feet and varies according to the seasons. In the rainy season, the depth of the pond is 10 feet, in winter months, it is about 8 feet and in summer, it is about 6 feet.

There is s continuous flow of water through inlets or outlets. The means by which the pond gets water into it is by Rainsand Godavari water through its irrigation canals. The level of the pond decreases not only due to seasonal variations but also due to drinking of water by the cattle and other animals that move around and, away. The surface area of the pond is sufficient. However the nature of the pond denotes that if it is not influenced by human beings because it is situated away from the human inhabitants.

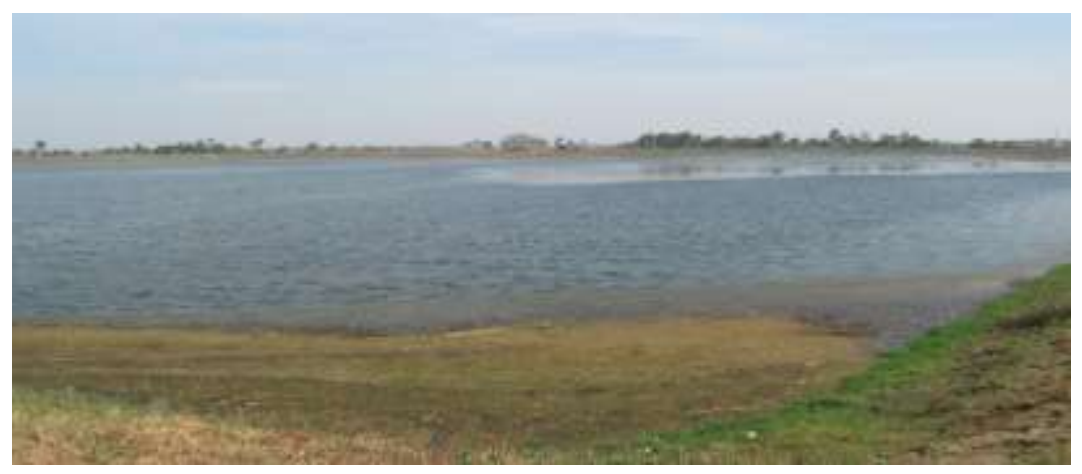

\section{Physiography:}

Light supply varies very much and is dependent upon the time of the day. One of the physical factors which has profoundous effect on the life of the pond is temperature. Temperature variations are tremendously great in the small water bodies like ponds, when compared to oceans.

When the trees are situated on its bank, naturally leaves fall into the water and gradually purification takes place. As a result the chemical nature of the pond is influenced to certain extent and dissolved nutrients are more in that condition. Such type of purification process is absent in this pond. As a results dissolved salts are very low. A glance at the pond, reveals that it is dominated by Frogs and during rainy season by leeches.

\section{Equipment And Method Of Collection:}

Apparatus and Chemicals needed:

[1] B.O.D. bottles $300 \mathrm{ml}-4$ Nos.

[2] Winchester bottle -2 litres -2 Nos.

[3] Plankton net 
[5] $\mathrm{pH}$ paper book

[6] Winkler's 'A' and 'B' reagents

\section{Fixation Of Oxygen On The Spot:}

The water sample is collected in to B.O.D. bottle slowly without agitation and then $2 \mathrm{ml}$ of Winkler's 'A' and $2 \mathrm{ml}$ of Winkler's 'B' are added slowly. The bottle is shakened well. The water samples should be collected only in to B.O.D. bottles to prevent photochemical reactions. Precaution should be taken to avoid dissolution of atmospheric oxygen in water samples. Then the sample is brought to the laboratory for analysis.

\section{Collection Of Water Sample For Other Expts:}

The water from the pond is collected slowly into a two litre Winchester bottle and this is used for the estimation of other chemical parameters. In the laboratory parameters like $\mathrm{pH}$, temperature, dissolved oxyen, carbon dioxide, carbonates, bicarbonates and chlorides have been estimated by using standard methods.

\section{Correlations:}

The variations are very important when considering the functional aspect of ecosystem. Variations are generally of different types. Then may be either physio-chemical or biological. On analysis of pond we found the factors like $\mathrm{pH}$, temperature, dissolved oxygen, carbondioxide, Carbonates, bicarbonates and chlorides has profound influence on the living beings of the ecosystem.

\section{HYDORGEN ION CONCENTRATION (Ph):}

In fresh water environment $\mathrm{pH}$ is a determining factor for the biota by becoming a limiting factor. The $\mathrm{pH}$ value of different water bodies may fluctuate seasonally and annually. On examining, we observed a marked difference between surface water and deeper waters for about 2.2 units. The maximum $\mathrm{pH}$ recorded in our pond water is 7.3 and the minimum $\mathrm{pH}$ value is 6.4 with a range of 0.7 . In general there is not much variation in the pond with respect to $\mathrm{pH}$ values recorded by different batch students; indicating the alkaline nature of the pond. This shows that the $\mathrm{pH}$ has got a very good buffering potentiality. Though the $\mathrm{pH}$ range is species, yet lower aquatic forms in general showed little reaction to alterations in $\mathrm{pH}$, while higher aquatic organisms like fishes respond quickly to little $\mathrm{pH}$ variations. Thus the $\mathrm{pH}$ of natural waters is an important environmental factor, the variations of which among other causes are linked with species composition and life processes of animal and plant communities inhabiting them.

\section{Temperature:}

The unique thermal properties of water are best demonstrated by the fresh water environment. Diurnal seasonal variations of temperature are very much evident in these environments than in marine environment. A diurnal variation range of $4.8-50 \mathrm{C}$ has been recorded in the pond. The temperature of pond water varies from time to time and also from season to season. During day time the temperature is high and is low at nights. In winter months there is a decrease in temperature and an increase in summer season. The high temperature during day time is due to high solar radiation. The low temperature in winter months, is because of the cool conditions prevailing throughout the day when compared to summer season. The temperature recorded during day time is $280 \mathrm{C}$ and at nights is $250 \mathrm{C}$. The temperature recorded in winter months is $180 \mathrm{C}$ and in summer it is about $320 \mathrm{C}$. The average diurnal variation is $30 \mathrm{C}$ and the average seasonal variation is $140 \mathrm{C}$.

The water temperature is almost higher than atmospheric temperature in the morning i.e., at 7 A.M. This is due to the fact that the water gains heat slowly and leaves it slowly unlike the atmospheric temperature where quick changes occur.

We have analysed the water samples during autumn (September), winter (December) and spring (February). The temperature of water recorded during autumn is $270 \mathrm{C}$, in winter $220 \mathrm{C}$ and in spring $290 \mathrm{C}$. We plotted a graph for the above data. According to the graph there are two peak points one in autumn and another in spring. With increase in temperature, the oxygen content was found decreased. This is due to the fact, that when temperature increases, the gas dissolved in water will escape into the atmosphere. When the temperature of the water is $220 \mathrm{C}$, the oxygen content is high $(7.06 \mathrm{mg} / \mathrm{L})$. In spring when the temperature is maximum i.e., $290 \mathrm{C}$ the oxygen content in the water is found low $(3.96 \mathrm{mg} / \mathrm{L})$.

In winter months due to low temperature the salinity is less $(0.3132 \mathrm{mg} / \mathrm{L})$ Land during spring season when the temperature is high, the salinity is more $(0.4261 \mathrm{mg} / \mathrm{L})$. This is due to evaporation of water during hot seasons. It is evident from the above data, the temperature has an inverse relationship with oxygen and direct relationship with salinity. 


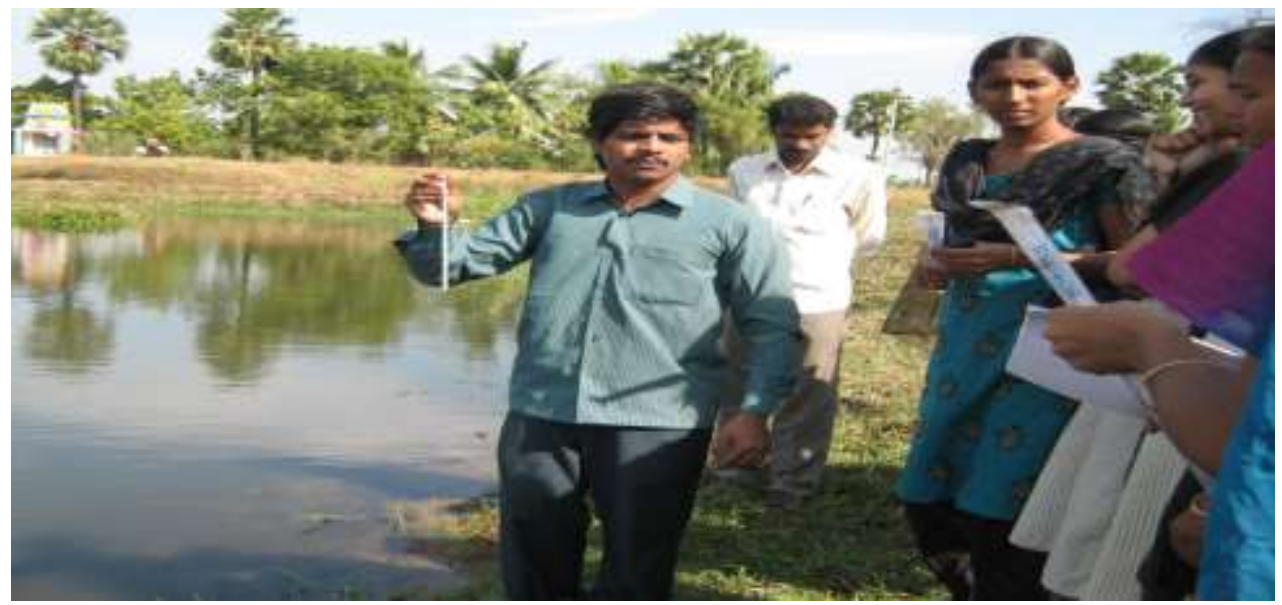

IV. Dissolved Oxygen:

Oxygen plays an important role on the metabolic and physiological activities of the organisms and thus the availability of oxygen affects the organisms. The oxygen supply for the aquatic animals comes chiefly by diffusion from air and oxygen released during photosynthesis by the aquatic plants. Primarily oxygen is utilized by the organisms during respiration and decomposition of organic water.

The volume of oxygen dissolved in water is dependent upon - (i) its tempera-ture (ii) the portial pressure of of oxygen in the air in contact with water at the surface and, (iii) the concentration of dissolved salts. Under a given set of conditions, there is a non-linear inverse relation between the water temperature and dissolved oxygen.

When the temperature decreases, the oxygen content increases and vice versa. In our present study the temperature recorded in the month of September (Autumn) is 270C, in December (winter) 220C and in February (spring) it is $290 \mathrm{C}$. The oxygen content estimated in September is $5.67 \mathrm{mg} / \mathrm{L}$, in December it is $7.06 \mathrm{mg} / \mathrm{L}$ and in Febraury it is $3.96 \mathrm{mg} / \mathrm{L}$. From the above data it is clear, that with increase of temperature the oxygen content is decreased and vice versa. This is due to lesser solubility of gas in winter at higher temperature. The oxygen concentration decreases with increase in the salinity.

\section{Carbondioxide:}

Aquatic vegetation and phytoplankton require carbondioxide for photosynthetic activity. The carbondioxide in fresh water environment is produced as the end product of respiration and of decomposition of organic matter. Carbondioxide also diffuses directly from the atmosphere and readily dissolved in water to result in carbonic acid ( $\mathrm{H} 2 \mathrm{Co} 3)$, which affects the $\mathrm{pH}$ of water. It is also present in the freshwater as carbonates and bicarbonates of calcium, magnesium and other minereals.

In the present study, the carbondioxide content estimated in September is $2.9 \mathrm{mg} / \mathrm{L}$, in December it is $2.2 \mathrm{mg} / \mathrm{L}$ and in February it is $3.48 \mathrm{mg} / \mathrm{L}$. From the above data it is clear that carbondioxide has direct relationship with temperature and inverse relationship with dissolved oxygen.

When oxygen content is increased, the carbondioxide content decreased and vicerversa. It can be attributed to photosynthetic activity of phytoplankton and oxygens consumption during respiratory activity of the aquatic organisms. Since high $\mathrm{CO} 2$ concentrations are associated with low oxygen concentrations, fishes respond vigorously to high concentrations and may be killed. Few echinoderm larvae grow larger with increased carbondioxide tension.

Greater concentration of carbondioxide lowers the $\mathrm{pH}$ of the medium. If $\mathrm{pH}$ of the medium is high due to low concentration of carbondioxide, formation of calcium caronate $(\mathrm{CoCo} 3)$ is favoured. Relations of calcium carbonate and sea water are responsible for coral forming polyps and algae. Carbondioxide is necessary for proper growth of calcareous shell bearing organisms. Concentration of carbondioxide may change orientation of some organisms.

It is suggested that anadromous fishes like salmon pomolobus migrate towards the stream which contains low concentrations of $\mathrm{CO} 2$. When we correlate the $\mathrm{CO} 2$ values with temperature, it shows that an increase in temperature causes the loss of gas from the water and vice versa. Hence carbondioxide shows direct relation with temperature. 


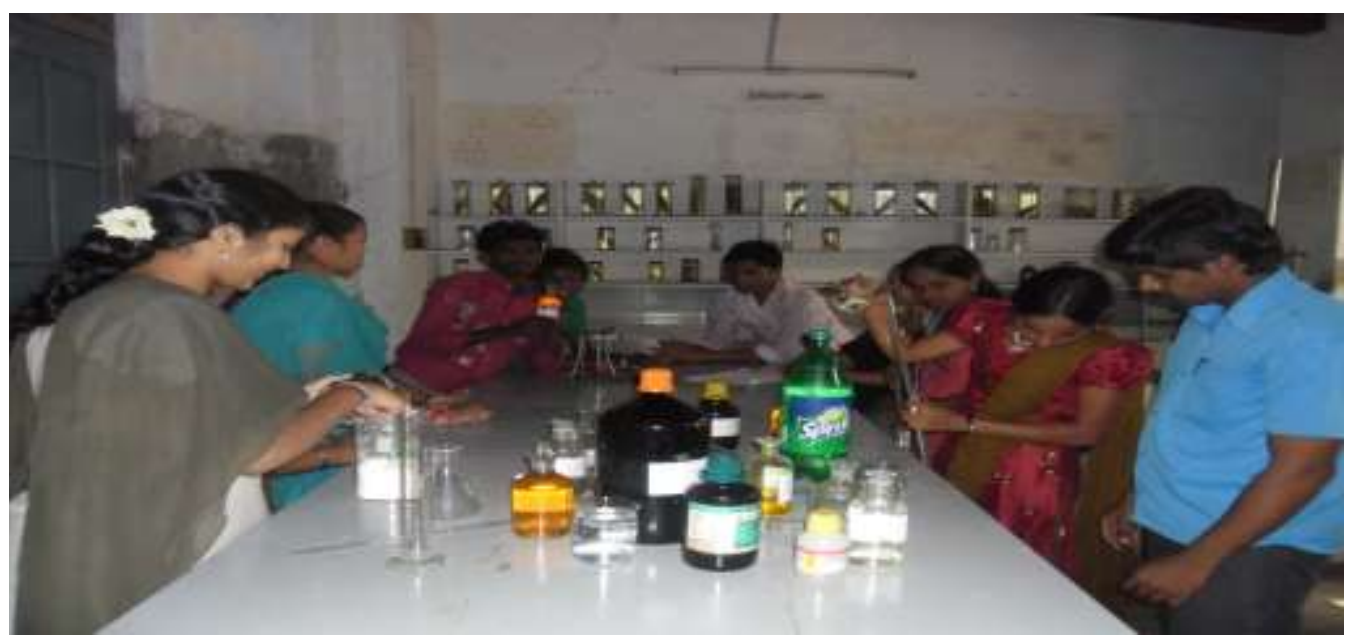

\section{Chlorides:}

Salinity of water is an important factor in maintaining proper osmotic relationship between the protoplasm of the organism and water. Salinity is a variable factor. It may vary according to the amount of various salts present in the medium. Inland natural waters, in general have low chloride concentration, often less than that of bicarbonates. However inland saline waters, coastal, estuarine and sea waters are characterized by moderate to very high chloride content. In natural fresh waters high concentration of chlorides is considered to be an indicator of pollution due to organic wastes.

At high temperature (in summer), most of the water may evaporate due to heat and water present in that area becomes more and more concentrated. Thus owing to evaporation, the salinity may increase. Similarly due to precipitation, the salinity may decrease. During rainy season due to dilution of water, the salinity becomes low. Salinity also affects the total amount of organic matter present in the pond. Greater the salinity content, the lesser will be the organic matter. Hence freshwater areas like lakes and ponds have greater amount of organic matter than in the sea water. Thus, salinity is a factor which varies according to the habitat and this is important in animal distribution.

In the present study we have estimated the salinity (chlorides) of various water samples viz., pond water, distilled water, brackish water and sea water, polluted water.

\begin{tabular}{|l|l|l|}
\hline Sl.No. & Sample & Salinity $\mathrm{mg} / \mathrm{L}$ \\
\hline 1. & Distilled Water & 0.1328 \\
\hline 2. & Pond Water & 0.3134 \\
\hline 3. & Brackish Water & 9.883 \\
\hline 4. & Sea Water & 37.5 \\
\hline 5. & Polluted Water & 245.63 \\
\hline
\end{tabular}

From the above data, it is clear that salinity of sea water is high due to presence of sodium chloride in large amount, than that of fresh water. The salinity of distilled water is very low than that of pond water and this is due to removal of salts from water by distillation. The salt content of brackishwater is $1 / 4$ th of sea water, since it is a mixture of sea and fresh waters. In polluted water the chloride content is very high due to the presence of organic wastes of animal origin.

\section{Carbonates And Bicarbonates:}

Amount of bound carbonates gives a good measure of hardness of water. In fresh water, the carbonates are mainly combined with $\mathrm{Ca}++$ and $\mathrm{Mg}++$ ions and causes calcium and magnesium hardness. A number of bases such as carbonates, bicarbonates, hydroxides, phosphates, nitrates etc., contribute to the alkalinity. However in natural waters, carbonates, bicarbonates and hydroxides are considered to be the predominant bases.

Hard water lakes are characterized by the negative values of free $\mathrm{CO} 2$ due to withdrawl of bicarbonates at a greater rate than carbonates precipitated and by $\mathrm{pH}$ ranging from about 8.5 upwards. Swingle suggested the titration end points to correspond the following $\mathrm{pH}$ values.

$\mathrm{pH}=5.0$ when total alkalinity is $30 \mathrm{ppm}$ as $\mathrm{CaCO}_{2}$.

$\mathrm{pH}=4.8$ when total alkalinity is $150 \mathrm{ppm}$ as $\mathrm{CaCO}_{3}$.

$\mathrm{pH}=4.5$ when total alkalinity is $500 \mathrm{ppm}$ as $\mathrm{CaCO}_{3}$. 
Hydroxide alkalinity generally occurs in polluted waters. A mixture of bicarbonate and carbonate alkalinity is generally encountered in water of $\mathrm{pH}$ ranging from 8.4 to 10.5 . Bicarbonates are reduced in higher $\mathrm{pH}$ values. At $\mathrm{pH}$ values less than 8.3 but more than 4.5 , practically no carbonate is present, but free $\mathrm{CO} 2$ and bicarbonates may present.

\section{References}

[1] Ecology :- Mohan. P. Arora, Published by Mrs. Meene panday, For Himalaya Publication House.

[2] Fresh water Fishery Biology :- KARAL E.LAGLER.Copyright@1952,1956 by karl f.lagle ISBN 0-697-04675-3, Fourteenth printing 1975, Printed in the united states of america. Salinity:- 283. (water), Alkalilnity (257-258), Carbon dioxide (254-255), PH (255-256), Dissolved oxygen ( 250-254).

[3] Aquaculture vol III:- Dr.K.Kondaina \$ k.swaroop kumar

[4] Systematic analytical chemistry :- SRIASTAVA KAMBOJ, Published by :- SHOBAN LAL NAGIN $\quad$ M -5 Industrial area A (296-300) DO(306-304), Chloride(304-305).

[5] Analytical chemistry :GARY D.Christain-5th Edition, Printed in India at Gopsons papers Ltd. Noida, Water analysis 635 pg.

[6] Fish and Fisheries of India :-V.G.JHINGRAN

[7] Kamble.S.M.;Kamble A.H. and Narke S.Y.(2009): study of physico-chemical parameters of Ruti dam,TQ.Ashti,dist.Beed,Maharashtra.J.AQUA. Biol. 86-89.

[8] Masood ahmed and krishnamurthy r.(1990).hydrobiological studies of wohar reservoir aurangabad(Maharashtra state) India. J.Environ. Biol 335-343.

[9] Hujare, M.S,(2008):Seasonal variation of physico-chemical parameters In the perennial tank of Talsande, Maharashtra.Eotoxicol.Environ. Monit. 18(3):233-242.

[10] Swaranlatha,S and a.Narsingrao.(1998):Ecological Studies of Banjara lake with reference to water pollution. J.Envi.Biol.19(2):179186. 